\title{
Intestinal permeability and inflammation in patients on NSAIDs
}

G Sigthorsson, J Tibble, J Hayllar, I Menzies, A Macpherson, R Moots, D Scott, M J Gumpel, I Bjarnason

\begin{abstract}
Background-The frequency with which non-steroidal anti-inflammatory drugs (NSAIDs) increase small intestinal permeability and cause inflammation is uncertain.

Aims-To examine small intestinal permeability and inflammation in a large number of patients on long term NSAIDs. Methods-Sixty eight patients receiving six different NSAIDs for over six months underwent combined absorptionpermeability tests at three different test dose osmolarities (iso-, hypo-, and hyperosmolar). Two hundred and eighty six patients on 12 different NSAIDs underwent indium-111 white cell faecal excretion studies to assess the prevalence and severity of intestinal inflammation.
\end{abstract}

Results-The iso- and hyperosmolar tests showed significant malabsorption of 3-0-methyl-D-glucose, D-xylose, and L-rhamnose. Intestinal permeability changes were significantly more pronounced and frequent with the hypo- and hyperosmolar as opposed to the isoosmolar test. Sequential studies showed that four and nine patients (of 13) developed inflammation after three and six months treatment with NSAIDs, respectively. There was no significant difference $(p>0.1)$ in the prevalence (54$72 \%$ ) or severity of intestinal inflammation in the 286 patients taking the various NSAIDs apart from those on aspirin and nabumetone, these having no evidence of intestinal inflammation. There was no significant correlation between the inflammatory changes and age, sex, dose of NSAID, length of disease, or NSAID ingestion.

Conclusions-Intestinal permeability test dose composition is an important factor when assessing the effects of NSAIDs on intestinal integrity. All the conventional NSAIDs studied were equally associated with small intestinal inflammation apart from aspirin and nabumetone which seem to spare the small bowel.

(Gut 1998;43:506-511)

Keywords: non-steroidal anti-inflammatory drug; intestinal permeability; intestinal inflammation; aspirin; nabumetone

Dr I Bjarnason, Department of Medicine, King's College School of Medicine and Dentistry, Bessemer Road, London SE5 9PJ, UK.

Accepted for publication 31 March 1998

Non-steroidal anti-inflammatory drugs (NSAIDs) are the most widely prescribed of the antirheumatic drugs, attesting to their effi- cacy as analgesic, anti-inflammatory, and antipyretic agents. A major concern with this group of drugs is the frequency and severity of gastrointestinal side effects. ${ }^{1}$ The precise magnitude of the problem is controversial and depends in part on the study population and/or the methods used to assess the damage. ${ }^{2}$

Most NSAIDs cause gastric damage in short term volunteer studies, ranging from erythema to ulcers. ${ }^{3}$ Cross sectional endoscopy studies in patients on long term NSAIDs show gastric erosions in $20-40 \%$ and gastric ulcers in $10-25 \%$ which have the potential to perforate and bleed. ${ }^{4-7}$ Small intestinal inflammation on the other hand is associated with blood and protein loss which may contribute to iron deficiency and hypoalbuminaemia..$^{8-10}$

The gastric damage induced by short term usage of NSAIDs seems to be dose and formulation dependent. ${ }^{3}$ In the long term, NSAID ingestion is associated with a roughly equal frequency of gastric damage irrespective of drug formulation. However there is a ranking order of NSAIDs when it comes to the serious complications of gastroduodenal bleeding and perforation: azapropazone, indomethacin, and piroxicam usually head the toxicity list while ibuprofen and aspirin seem to be safer, ${ }^{11-13}$ possibly because of the lower doses used. ${ }^{14}$

The role of individual NSAIDs in small intestinal damage in man is less well characterised because of the difficulties of documenting and quantitating damage. ${ }^{915}{ }^{16}$ Single dose volunteer studies show some difference in the potency of NSAIDs to increase intestinal permeability, ${ }^{17-19}$ but it is not known whether this applies to long term ingestion. Here various studies have suggested either a high prevalence of increased small intestinal permeability, ${ }^{20}$ no increased permeability, ${ }^{21}$ infrequent changes only, ${ }^{22}$ or even colonic rather than small bowel permeability changes. ${ }^{23}$ One possibility for these discrepancies is that the various permeability test procedures used may differ in respect of their sensitivity. Furthermore it is not known whether the severity of NSAID enteropathy relates to the particular NSAID taken.

This study is in two parts. The first part assesses the prevalence of increased intestinal permeability and the relative sensitivity of three different test doses in patients on long term NSAIDs in order to resolve the controversy relating to the extent of intestinal permeability changes in patients on NSAIDs. The second part concerns a large number of patients with rheumatoid arthritis and osteoarthrosis who underwent indium-111 white cell studies to 
Table 1 Compositions of the three test solutions used for the intestinal permeability studies

\begin{tabular}{llll}
\hline & $\begin{array}{l}\text { Hypo-osmolar } \\
(12 \mathrm{mmol} / \mathrm{l})\end{array}$ & $\begin{array}{l}\text { Iso-osmolar } \\
(244 \mathrm{mmol} / \mathrm{l})\end{array}$ & $\begin{array}{l}\text { Hyperosmolar } \\
(1500 \mathrm{mmol} / \mathrm{l})\end{array}$ \\
\hline 3-0-methyl-D-glucose & & $0.2 \mathrm{~g}$ & $0.2 \mathrm{~g}$ \\
$\begin{array}{l}\text { D-xylose } \\
\text { L-rhamnose }\end{array}$ & $1.0 \mathrm{~g}$ & $0.5 \mathrm{~g}$ & $0.5 \mathrm{~g}$ \\
Lactulose & $1.0 \mathrm{~g}$ & $1.0 \mathrm{~g}$ \\
${ }^{51}$ Cr-EDTA & $50-100 \mu \mathrm{Ci}$ & $5.0 \mathrm{~g}$ & $5.0 \mathrm{~g}$ \\
Glycerol & & $9.2 \mathrm{ml}$
\end{tabular}

Inclusion of 3-0-methyl-D-glucose allows assessment of active carrier mediated transport and D-xylose passive carrier mediated transport.

L-rhamnose assesses "small pore" predominantly non-mediated transcellular transport and lactulose and ${ }^{51} \mathrm{Cr}$-EDTA assess non-mediated "large pore" paracellular transport. ${ }^{33}$ The differential urinary excretion of ${ }^{51} \mathrm{Cr}-\mathrm{EDTA} / \mathrm{L}$-rhamnose or lactulose/L-rhamnose provides a specific index of intestinal permeability.

assess the prevalence and severity of NSAID enteropathy and to establish whether there is a ranking order of toxicities for different NSAIDs in the small intestine.

\section{Patients and methods}

INTESTINAL PERMEABILITY

Fourteen healthy Caucasian volunteers acted as controls for these studies (seven males and seven females, mean age 42 years, range 22-63 years). They were not receiving any treatment known to be associated with alterations in gastrointestinal function or gastrointestinal side effects. ${ }^{24}$

Sixty eight Caucasian patients with definite or classic rheumatoid arthritis $(n=54)$ (American Rheumatism Association criteria) and osteoarthrosis $(n=14)$ taking the same NSAID consistently for over six months were studied (16 males and 52 females, mean age 63 years, range $26-81$ years). They were recruited from the rheumatology outpatient clinics at Northwick Park Hospital and King's College Hospital. Patients were specifically excluded from study if they had significant cardiovascular, pulmonary, liver, or renal disease, or malignancy, or were receiving oral gold, sulphasalazine, or more than one NSAID. ${ }^{25}$ Patients receiving other drugs or those with other diseases associated with increased intestinal permeability $^{24}$ were also excluded. All were admitted to a metabolic research ward during these studies.

Sixteen patients were on regular indomethacin $(100-150 \mathrm{mg} /$ day), 16 on naproxen (1000-1500 mg/day), 13 on piroxicam (10-20 $\mathrm{mg} /$ day), 11 on ibuprofen (1200-2400 mg/ day), seven on flurbiprofen (50-300 mg/day), and six on sulindac (300-400 mg/day).

Each patient fasted overnight and took their particular NSAID at $700 \mathrm{am}$. This was followed by the ingestion of a $100 \mathrm{ml}$ test solution at 800 am and a further two hour fast after which food and fluid were allowed. Complete five hour urine collections were made into a container containing $1 \mathrm{ml}$ thiomersal (10\% $\mathrm{wt} / \mathrm{vol}$ aqueous) as preservative.

Table 1 shows the composition of the three test solutions used. The use of the four sugars in the iso- and hyperosmolar test solution allows the simultaneous assessment of four absorption-permeation pathways. The osmolarities were decided on the basis that these represent the most common test dose osmolarities used in studies of intestinal absorption- permeability and test dose osmolarity may play an important role in the sensitivity of the procedure. ${ }^{2627}$ The tests were administered in random sequence, at least two days apart.

Sugar analysis in urine was performed by thin layer chromatography as previously described $^{2829}$ with scanning densitometry. These procedures are accurate and sensitive, recovery being above $90 \%$ and minimum level of reliable quantitation below $0.1 \mathrm{mmol} / \mathrm{l}$. The precision lies between 3 and $8 \%$ (coefficient of variation) without replication over the test range of sugar concentration. The urine $(5 \mathrm{ml}$ aliquots) containing ${ }^{51} \mathrm{Cr}$-EDTA was counted in an LKB Wallac 1280 or 1282 (UpjohnPharmacia, Helsinki, Finland) along with a $1 / 500$ dilution of the original test solution. Each sample was counted for five minutes which allows the minimum detectable activity of $0.03-0.05 \%$ of the administered test dose per litre of urine to be measured.

\section{INTESTINAL INFLAMMATION}

Twenty two patients (mean age 38 years, range 20-65 years) with irritable bowel syndrome acted as controls for the ${ }^{111}$ In white cell studies. Twelve and eight patients with untreated rheumatoid arthritis and osteoarthritis, respectively, acted as disease controls (mean age 56 years, range 23-83 years).

\section{Sequential studies}

Thirteen of the patients not on NSAIDs (seven with rheumatoid arthritis and six with osteoarthritis) underwent sequential ${ }^{111}$ In white cell studies before, and three, and six months after starting indomethacin 100-150 mg/day (seven patients) or piroxicam 10-20 mg/day (six patients) and no other drugs, in order to assess the temporal relation between NSAID ingestion and the development of intestinal inflammation.

Cross sectional studies

The cross sectional study involved 286 patients (57 males and 229 females, mean age 62 years, range 18-86 years) with rheumatoid arthritis $(n=253)$ and osteoarthrosis $(n=33)$, taking the same NSAID consistently for over three months. These were recruited from the rheumatology outpatient clinics at Northwick Park Hospital and King's College Hospital. All but 31 investigations were carried out as inpatients in a metabolic research ward. Exclusion criteria were the same as for the intestinal permeability studies.

The patients were on conventional NSAIDs: indomethacin 100-150 mg/day ( $\mathrm{n}=52)$, naproxen $1000-1500 \mathrm{mg} /$ day $(\mathrm{n}=58)$, piroxicam 10-20 mg/day ( $\mathrm{n}=28)$, ibuprofen 1200 $2400 \mathrm{mg} /$ day $(\mathrm{n}=29)$, flurbiprofen 100-200 $\mathrm{mg} /$ day $(\mathrm{n}=16)$, ketoprofen 600-1200 mg/day $(n=14)$, diclofenac $75-150 \mathrm{mg} /$ day $(\mathrm{n}=38)$, and aspirin $(n=7)$; or pro-NSAIDs: sulindac 300-400 mg/day ( $\mathrm{n}=9)$, etodolac 400-600 $\mathrm{mg} /$ day $(\mathrm{n}=11)$, fenbufen $600-900 \mathrm{mg} /$ day $(n=11)$, or nabumetone $2 \mathrm{~g} /$ day $(n=13)$. 
Table 2 Intestinal absorptive capacity and intestinal permeability assessed at three different test dose osmolarities

\begin{tabular}{|c|c|c|c|c|c|c|c|}
\hline & Control & Indomethacin & Piroxicam & Naproxen & Ibuprofen & Flurbiprofen & Sulindac \\
\hline \multicolumn{8}{|l|}{ Iso-osmolar test } \\
\hline 3-0-methyl-D-glucose & $43.6(6.8) \%$ & $28.9(8.5) \%^{\star}$ & $31.0(9.9) \% \star$ & $24.6(7.7) \%^{\star}$ & $24.7(10.6) \%^{\star}$ & $29.2(11.5) \%$ & $24.8(9.4) \%^{\star}$ \\
\hline D-xylose & $29.5(3.2) \%$ & 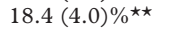 & $20.9(7.9) \%$ * & 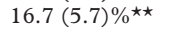 & $20.2(13.9) \%$ * & $22.2(4.4) \%$ * & $18.3(7.7) \% \star$ \\
\hline L-rhamnose & $10.5(1.9) \%$ & $7.7(2.6) \% \star$ & 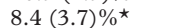 & 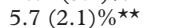 & $6.5(4.3) \% \star$ & $7.2(3.1) \%$ & $6.9(2.8) \%$ \\
\hline Lactulose & $0.267(0.110) \%$ & $0.356(0.185) \%$ & $0.416(0.338)$ & $0.212(0.085) \%$ & $0.280(0.140$ & $0.401(0.219) \%$ & $0.338(0.231) \%$ \\
\hline $\begin{array}{l}\text { Lactulose:L-rhamnose } \\
\text { Hyperosmolar test }\end{array}$ & $0.029(0.010)$ & $0.056(0.041)^{\star}$ & $0.057(0.045)^{\star}$ & $0.057(0.062)^{\star}$ & $0.054(0.029)^{\star}$ & $0.060(0.044)^{\star}$ & $0.056(0.064)^{\star}$ \\
\hline 3-0-methyl-D-glucose & $43.7(4.7) \%$ & $29.0(11.3) \%^{\star}$ & $26.8(11.3) \%$ * & $29.3(10.8) \%$ & $27.5(9.7) \% \star$ & $28.3(13.2) \%^{\star}$ & $30.1(5.2) \% \star$ \\
\hline D-xylose & $30.2(4.8) \%$ & 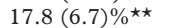 & 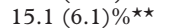 & 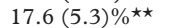 & $17.1(7.07) \%$ * & $25.7(8.8) \%$ & $19.9(8.5) \%$ * \\
\hline L-rhamnose & $11.1(2.1) \%$ & $6.7(2.3) \% \star$ & $6.3(2.9) \%^{\star}$ & $6.7(1.7) \% \star$ & $7.8(3.9) \% \star$ & $5.8(3.2) \%^{\star}$ & $6.2(5.1) \%^{\star}$ \\
\hline Lactulose & $0.361(0.100) \%$ & $0.775(0.451) \%^{\star}$ & $0.588(0.265) \%$ & $0.702(0.434) \%^{\star}$ & $0.844(0.715) \%$ * & $0.775(0.331) \%$ & $0.619(0.444) \%$ \\
\hline $\begin{array}{l}\text { Lactulose:L-rhamnose } \\
\text { Hypo-osmolar test }\end{array}$ & $0.034(0.011)$ & $0.127(0.099)^{\star \star}$ & $0.091(0.048)^{\star \star}$ & $0.106(0.060)^{\star \star}$ & $0.107(0.074)^{\star \star}$ & $0.112(0.065)^{\star \star}$ & $0.097(0.081)^{\star \star}$ \\
\hline L-rhamnose & $12.3(2.4) \%$ & $10.8(2.8) \%$ & $9.20(3.73) \%$ & $10.2(5.2) \%$ & $10.1(5.0) \%$ & $12.1(4.8) \%$ & $11.6(3.6) \%$ \\
\hline${ }^{51} \mathrm{Cr}-\mathrm{EDTA}$ & $0.61(0.26) \%$ & $1.33(0.71) \%$ * & $1.13(0.52) \%$ * & $1.16(0.79) \%$ * & $0.72(0.37) \%$ & $1.29(0.63) \%$ * & $1.15(0.89) \%$ * \\
\hline${ }^{51} \mathrm{Cr}$-EDTA:L-rhamnose & $0.05(0.02)^{\star \star}$ & $0.13(0.06)^{\star \star}$ & $0.10(0.05)^{\star \star}$ & $0.12(0.06)^{\star \star}$ & $0.12(0.08)^{\star \star}$ & $0.14(0.09)^{\star \star}$ & $0.11(0.05)^{\star \star}$ \\
\hline
\end{tabular}

Values represent mean (SD) five hour urinary excretion (\% dose) or differential excretion of the test probes.

${ }^{\star}$ Differs significantly (ANOVA) from control, $\mathrm{p}<0.05$.

$\star \star$ Differs significantly (ANOVA) from control, $\mathrm{p}<0.01$.

\section{Cell labelling}

Neutrophils were isolated by sedimentation and centrifugation and labelled with ${ }^{111}$ In $(30-$ $300 \mu \mathrm{Ci}(1-11 \mathrm{MBq}))$ using tropolone as an ionophore as previously described ${ }^{15}$ and injected intravenously. The estimated radiation dose received during these studies was 0.7-6.5 millisieverts (effective dose equivalent). The higher dose of ${ }^{111}$ In was used if abdominal scintigraphy was performed and the lower dose if the study was confined to stool collections.

Individual stools were collected over a four day period after injection of the labelled cells and counted in a high resolution bulk sample counter along with standards for 20-60 seconds to allow measurement of $0.1-0.01 \%$ (low and high dose, respectively) of the injected dose with a counting accuracy of $\pm 4 \%$.

\section{STATISTICS}

The SYSTAT statistic package (for the Macintosh) was used for calculations. Spearman's correlation coefficient was used to assess correlations. The paired Student's $t$ test was used for sequential studies, one way analysis of variance (ANOVA) for assessing differences between groups, or $\chi^{2}$ test as appropriate.

\section{Results}

INTESTINAL ABSORPTIVE CAPACITY AND

INTESTINAL PERMEABILITY

Iso-osmolar test solution

Table 2 shows the five hour urinary excretion of 3-0-methyl-D-glucose, D-xylose, and L-rhamnose and the differential urinary excretion of lactulose:L-rhamnose. Patients on NSAIDs excreted significantly less $(p<0.05)$ monosaccharides than controls; two to seven patients (33-43\%) in each group had levels below the control lower limits (below -2SD).

The excretion of lactulose did not differ significantly from control levels, but intestinal permeability as assessed by the differential urinary excretion of lactulose:L-rhamnose was significantly $(p<0.05)$ increased with an average twofold increase from control levels. Three to five patients $(24-50 \%)$ in each group had values above the control range. There were no significant differences $(p>0.2)$ in the frequency or severity of the permeability changes in patients receiving the different NSAIDs.
Hyperosmolar solution

Control excretion values for monosaccharides and intestinal permeability did not differ significantly from the iso-osmolar test dose (table 2). Monosaccharide excretion was significantly $(p<0.05)$ decreased in patients on NSAIDs compared with controls and the same patients had values outside the lower limit as with the iso-osmolar test.

The differential urinary excretion of lactulose:L-rhamnose was significantly $(p<0.05)$ increased in each group of patients on NSAIDs. In each group, $50-81 \%$ of patients had values above the control range which was significantly $(p<0.02)$ greater than that following the isoosmolar test.

There were no significant differences in absorptive capacity or the differential urinary excretion of lactulose:L-rhamnose between patients on different NSAIDs.

Hypo-osmolar test

The urinary excretion of L-rhamnose did not differ significantly from control levels in any of the patient groups on NSAIDs (table 2). The differential excretion of ${ }^{51} \mathrm{Cr}$-EDTA:Lrhamnose was significantly increased in each group of patients on NSAIDs. The discrimination between controls and patients on NSAIDs (50-90\% of patients in each group) was comparable with that obtained with the hyperosmolar test and significantly $(\mathrm{p}<0.01)$ greater than with the iso-osmolar test dose. There were however no significant differences $(p>0.3)$ in the frequency or severity of the permeability changes in subjects on different NSAIDs as assessed by the differential urinary excretion of ${ }^{51} \mathrm{Cr}-\mathrm{EDTA}: \mathrm{L}-\mathrm{rhamnose}$.

\footnotetext{
${ }^{111}$ In WHITE CELL STUDIES
}

The mean (SD) normal four day faecal excretion of ${ }^{111}$ In white cells was $0.46(0.23) \%$ (range $0.05-0.98 \%$ ) of the injected dose. The absolute upper limit $(0.98 \%)$ was used to define normal-abnormal excretion of ${ }^{111} \mathrm{In}$ white cells.

Patients with untreated rheumatoid or osteoarthritis had mean ${ }^{111} \mathrm{In}$ excretion values $(0.59$ $(0.31) \%$, range $0.09-1.21 \%$ ) which did not differ significantly $(p>0.6)$ from normal controls. 


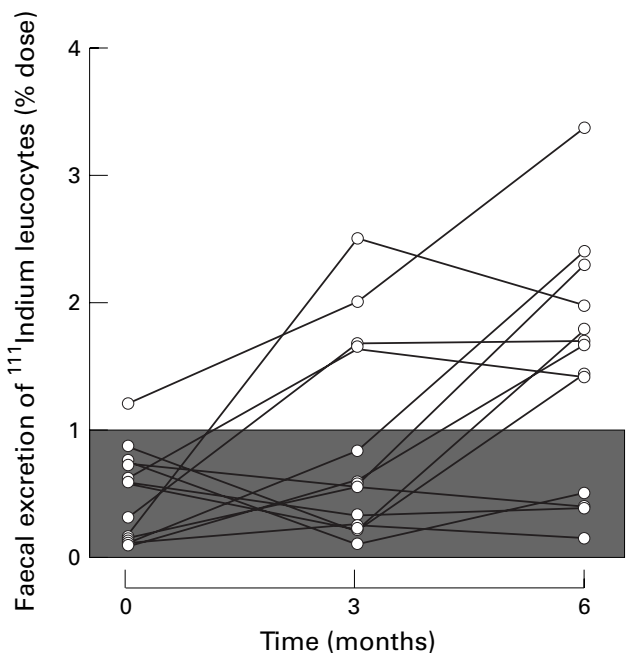

Figure 1 Sequential changes in the four day faecal excretion of ${ }^{11}$ In white cells in response to indomethacin or piroxicam ingestion. The shaded area represents the normal range of excretion of the labelled cells.

Sequential studies

Figure 1 shows the sequential changes in the faecal excretion of ${ }^{111} \mathrm{In}$ in subjects taking indomethacin or piroxicam. By three months on the drugs four patients were clearly abnormal and at six months nine of 13 had intestinal inflammation.

\section{Cross sectional studies}

Table 3 shows that the mean four day faecal excretion of ${ }^{111}$ In white cells was significantly $(p<0.05)$ increased in patients taking different NSAIDs except in those on aspirin and nabumetone who did not differ significantly from controls (one of seven on aspirin and two of 13 patients on nabumetone had intestinal inflammation as assessed by the faecal excretion of ${ }^{111}$ In white cells).

There was no significant difference $(p>0.1)$ in the prevalence of intestinal inflammation in patients taking the various NSAIDs (apart from aspirin and nabumetone), the proportion of patients with abnormal results being 54$72 \%$. Within each group of patients on NSAIDs there was no significant correlation $(r$ ranged from -0.11 to $0.17, \mathrm{p}>0.1$ ) between the faecal excretion of ${ }^{111}$ In and age, sex, dose of NSAID, length of disease, or NSAID ingestion.

Table 3 Intestinal inflammation in patients on long term NSAIDs

\begin{tabular}{lccl}
\hline & No studied & No abnormal & $\begin{array}{l}4 \text { day faecal excretion of } \\
{ }^{11} \text { In white cells (\% dose) }\end{array}$ \\
\hline Normal controls & 22 & 0 & $0.5(0.2) \%$ \\
Patient controls & 20 & 3 & $0.6(0.3) \%$ \\
Indomethacin & 52 & 30 & $4.1(2.9) \%^{\star}$ \\
Piroxicam & 28 & 15 & $3.9(1.1) \%^{\star}$ \\
Naproxen & 58 & 42 & $3.9(0.8) \%^{\star}$ \\
Ibuprofen & 29 & 16 & $3.0(1.2) \%^{\star}$ \\
Flurbiprofen & 16 & 9 & $4.5(3.2) \%^{\star}$ \\
Ketoprofen & 14 & 9 & $3.5(1.8) \%^{\star}$ \\
Diclofenac & 38 & 24 & $4.4(4.8) \%^{\star}$ \\
Aspirin & 7 & 5 & $0.7(0.3) \%^{\star}$ \\
Sulindac & 9 & 7 & $2.5(1.9) \%^{\star}$ \\
Etodolac & 11 & 6 & $3.7(2.1) \%^{\star}$ \\
Fenbufen & 11 & 2 & $2.7(2.3) \%^{\star}$ \\
Nabumetone & 13 & & $1.1(0.4) \%$
\end{tabular}

Values represent mean (SD) faecal excretion of ${ }^{111}$ Indium labelled neutrophils (\% dose) following intravenous instillation.

${ }^{\star}$ Differs significantly (ANOVA) from normal and patient controls, $\mathrm{p}<0.05$.

\section{Discussion}

The present study shows that long term NSAID ingestion is associated with mild malabsorption and that the different formulations of intestinal absorption/permeability tests vary in their sensitivity to detect the effects of NSAIDs on the small intestine. Sequential studies of patients receiving NSAIDs show that ingestion of the drugs leads to intestinal inflammation. The prevalence and intensity of the inflammation associated with different NSAIDs, apart from nabumetone and aspirin, is comparable.

Intestinal permeability is thought to be a prerequisite for the development of NSAID enteropathy. ${ }^{24} 3031$ However, there is a wide discrepancy in the reported prevalence of permeability changes in patients on NSAID treatment, ranging from $80 \%$ to nil. ${ }^{21}{ }^{23}$ The reason for these discrepancies is not clear. ${ }^{24}{ }^{32}$ The present study shows a notable difference in the sensitivity of the different test procedures which depends on test dose composition. Such differences in sensitivity may explain the failure of some studies to show significant effects of NSAIDs on small intestinal permeability, ${ }^{212326}$ especially as iso-osmolar test solutions were used. Others used a hyperosmolar test solution, ${ }^{22}$ achieved by addition of lactose and sucrose, intestinal hydrolysis of which introduces a variable which has considerable indirect effects on absorption and permeability estimations. ${ }^{32-35}$ The way in which different dose osmolarities affect the sensitivity of absorption/permeability the tests is complex, ${ }^{36-38}$ but it is suggested that the hypo- $(14 \mathrm{mmol} / \mathrm{l})$ and hyperosmolar (1500 $\mathrm{mmol} / \mathrm{l}$ ) solutions exert a physiological stress on the intestinal mucosa. A damaged or diseased intestinal mucosa may be more susceptible to such effects. ${ }^{26}{ }^{36-38}$

NSAIDs do not cause malabsorption when given short term, ${ }^{18}{ }^{19}$ but malabsorption of $\mathrm{D}$-xylose has been documented in patients on long term NSAID treatment. ${ }^{39}$ Here we show that the absorption of 3-0-methyl-D-glucose and L-rhamnose is also affected, but the malabsorption is relatively mild, ${ }^{40}$ and certainly insufficiently severe to cause malnutrition by itself.

The sequential study shows a $12-24$ week time interval between commencement of NSAID treatment and the development of intestinal inflammation. This contrasts with the demonstration of intestinal inflammation within two weeks of NSAID ingestion when the faecal calprotectin concentration is used as a marker of intestinal inflammation. ${ }^{42}$ The reason for these differences is uncertain. One possibility is that the ${ }^{111} \mathrm{In}$ white cell technique may underestimate somewhat the severity of intestinal inflammation as in active arthritis there is often increased synovial, liver, and splenic sequestration of the cells which would reduce the number available for migration to the intestine.

The cross sectional study showed no significant differences (apart from aspirin and nabumetone) in the frequency or severity of intestinal inflammation in patients on 
conventional NSAIDs or pro-NSAIDs. This is in contrast to the different toxicity of NSAIDs according to serious gastroduodenal outcomes (perforation and massive bleeding). ${ }^{112}$ The reasons for these apparent differences are likely to be methodological as well as biological. ${ }^{8}{ }^{16}$ In respect of the gastroduodenal mucosa, short term endoscopy studies give different NSAID toxicity rankings from the serious outcome studies. ${ }^{311}{ }^{12}$ At the same time cross sectional endoscopy studies do not shown a significant difference in the prevalence of gastroduodenal ulcers in patients on different NSAIDs ${ }^{43-46}$ which is in general agreement with what we have found in the small intestine. A potential problem with the above long term studies is the variability in the daily dose of NSAIDs which might obscure a dose effect relation if one existed. Nevertheless it seems likely that the particular factors which determine the development of gastroduodenal ulceration and small intestinal inflammation in patients on long term NSAID treatment differ from those that account for the short term gastroduodenal lesions and the predisposition of ulcers to bleed and perforate in the longer term.

In our study two NSAIDs were associated with less small intestinal inflammation than the others, namely aspirin and nabumetone. Interestingly the same drugs do not increase small intestinal permeability in $\operatorname{man}^{19}$ or cause small intestinal inflammation in the experimental rat even at very large doses. ${ }^{47-49}$ The possible reasons for the lack of small intestinal inflammation associated with these drugs may relate to their site of absorption and lack of excretion in bile. Aspirin, an acidic NSAID, is mostly absorbed through the gastroduodenal mucosa, ${ }^{50} 51$ while nabumetone is non-acidic and therefore not trapped within enterocytes during drug absorption. Aspirin and 6-methoxy-2-naphthylacetic acid, the active metabolite of nabumetone, are the two NSAIDs that are not excreted in bile in significant amounts. ${ }^{47} 52$ Hence the small intestinal mucosa may not be exposed to significant quantities of these drugs so that the "topical" phase of damage is largely avoided. ${ }^{31} 49$ At this conjecture it is relevant that cyclooxygenase-1 knockout mice, that produce virtually no intestinal prostaglandins, do not develop gastrointestinal lesions spontaneously, ${ }^{54}$ reemphasising that simple inhibition of cyclooxygenase is insufficient by itself to account for all of the gastrointestinal damage of NSAIDs. ${ }^{48556}$

In summary, these studies show that intestinal permeability test dose composition and osmolarity are important factors when assessing the possible effects of NSAIDs on intestinal integrity. Long term ingestion of all the conventional NSAIDs studied was equally associated with small intestinal inflammatory changes apart from aspirin and nabumetone, both of which seem to spare the small bowel.

GS was supported by the Helga Jonsdottir and Sigurlidi Kristjansson Memorial Fund, Iceland, and JT by an NHS Executive R\&D grant.
1 Barrier $\mathrm{CH}$, Hirschowitz BI. Current controversies in rheumatology. Controversies and management of nonsteroidal anti-inflammatory drug induced side effects on
upper gastrointestinal tract. Arthritis Rheum 1989;32:926-

2 Hayllar J, Macpherson A, Bjarnason I. Gastroprotection and nonsteroidal anti-inflammatory drugs. Drug Safety 1992;7:86-105

3 Lanza FL. A review of gastric ulcer and gastroduodenal injury in normal volunteers receiving aspirin and other non-steroidal anti-inflammatory drugs. Scand $\mathcal{f}$ Gastroenterol 1988;24(suppl 163):24-31.

4 Beardon PHG, Brown SV, Mcdevitt DG. Gastrointestinal events in patients prescribed NSAIDs: a controlled study using record linkage in Tayside. $O F$ Med 1989;71:497505.

5 Armstrong CP, Blower AL. Nonsteroidal anti-inflammatory drugs and life threatening complications of peptic ulcer disease. Gut 1987;28:527-32.

6 Pincus T, Callahan LF. Taking mortality in rheumatoid arthritis seriously-predictive markers, socioeconomic status and comorbidity. F Rheumatol 1986;14:841-5.

7 Mitchell DM, Spitz PW, Young DY, et al. Survival, prognosis, and causes of death in rheumatoid arthritis. Arthritis Rheum 1986;29:706-14.

8 Bjarnason I, Hayllar J, Macpherson AJ, et al. Side effects of nonsteroidal anti-inflammatory drugs on the small and large intestine. Gastroenterology 1993;104:1832-47.

9 Morris AJ, Wasson LA, Mackenzie JF. Small bowel enteroscopy in undiagnosed gastrointestinal blood loss. Gut 1992; 33:887-9.

10 Morris AJ, Madhok R, Sturrock RD, et al. Enteroscopic diagnosis of small bowel ulceration in patients receiving non-steroidal antiinflammatory drugs. Lancet 1991;337: 520.

11 Langman MJS, Weil J, Wainwright P, et al. Risk of bleeding peptic ulcers associated with individual non-steroidal antiinflammatory drugs. Lancet 1994;343:1075-8.

12 Rodrigues LAG, Jick H. Risk of upper gastrointestinal bleeding and perforation associated with individual nonsteroidal anti-inflammatory drugs. Lancet 1994;343:76972 .

13 Fries JF, Miller SR, Spitz PW, et al. Toward an epidemiology of gastropathy associated with non-steroidal antiinflammatory drug use. Gastroenterology 1989;96(suppl): 647-55.

14 Henry D, Lim LL-Y, Rodrigues LAG, et al. Variability in risk of gastrointestinal complications with individual non-steroidal anti-inflammatory drugs: results of a collaborative meta-analysis. $B M \mathcal{F}$ 1996;312:1563-6.

15 Bjarnason I, Zanelli G, Smith $\mathrm{T}$, et al. Nonsteroidal antiinflammatory drug induced intestinal inflammation in humans. Gastroenterology 1987;93:480-9.

16 Wallace JL. Nonsteroidal anti-inflammatory drugs and gastroenteropathy: the second hundred years. Gastroenterolgastroenteropathy: the

17 Bjarnason I, Williams P, Smethurst P, et al. The effect of NSAIDs and prostaglandins on the permeability of the human small intestine. Gut 1986;27:1292-7.

18 Bjarnason I, Smethurst P, Fenn GC, et al. Misoprostol reduces indomethacin induced changes in human small intestinal permeability. Dig Dis Sci 1989;34:407-11.

19 Bjarnason I, Fehilly B, Smethurst P, et al. The importance of local versus systemic effects of non-steroidal antiinflammatory drugs to increase intestinal permeability in man. Gut 1991;32:275-7.

20 Bjarnason I, Williams P, So A, et al. Intestinal permeability and inflammation in rheumatoid arthritis; effects of non-steroidal anti-inflammatory drugs. Lancet 1984;ii: non-ster

21 Struthers GR, Andrews DJ, Gilson RJC, et al. Intestinal permeability. Lancet 1985;i:587-8.

22 Juby LD, Axon ATR, Wright V, et al. Intestinal permeability and inflammation in rheumatoid arthritis. $\mathrm{Br} \mathcal{F}$ Rheumatol 1986;25:226-7.

23 Jenkins AP, Trew DR, Crump BJ, et al. Do nonsteroidal anti-inflammatory drugs increase colonic permeability? Gut 1991;32:66-9.

24 Bjarnason I, Macpherson A, Hollander D. Intestinal permeability: an overview. Gastroenterology 1995;108:156681.

25 Hayllar J, Smith T, Macpherson A, et al. NSAID-induced small intestinal inflammation and blood loss: the effect of sulphasalazine and other disease modifying drugs. Arthritis Rheum 1994;37:1146-50.

26 Bjarnason I, Maxton D, Reynolds AP, et al. A comparison of 4 markers of intestinal permeability in control subjects and patients with coeliac disease. Scand F Gastroenterol 1994;26: $630-9$

27 Maxton DG, Bjarnason I, Reynolds AP, et al. Lactulose, ${ }^{51}$ Cr-EDTA, L-rhamnose and polyethylene glycol 400 as probe markers for "in vivo" assessment of human intestinal permeability. Clin Sci 1986;71:71-80.

28 Menzies IS, Mount JN, Wheeler MJ. Quantitative estimation of clinically important monosaccharides in plasma by rapid thin layer chromatography. Ann Clin Biochem 1978;15:65-76.

29 Teahon K, Smethurst P, Levi AJ, et al. Intestinal permeability in patients with Crohn's disease and their first degree relatives. Gut 1992;33:320-3.

30 Bjarnason I, Macpherson A, Somasundaram S, et al. Nonsteroidal anti-inflammatory drugs and inflammatory bowel disease. Can $\mathcal{F}$ Gastroenterol 1993;7:160-9. 
31 Somasundaram S, Hayllar J, Rafi S, et al. The biochemical basis of NSAID-induced damage to the gastrointestinal tract: a review and a hypothesis. Scand $\mathcal{f}$ Gastroenterol 1995 30:289-99.

32 Travis S, Menzies IS. Intestinal permeability: functional assessment and significance. Clin Sci 1992;82:471-88.

33 Menzies IS. Transmucosal passage of inert molecules in health and disease. In: Skadhauge $\mathrm{E}$, Heintze K, eds. Intestinal absorption and secretion. Falk Symposium 36 Lancaster: MTP Press, 1984:527-43.

34 Menzies IS, Jenkins AP, Heduan E, et al. The effect of poorly absorbed solute on intestinal absorption. Scand 7 Gastroenterol 1990;25:1257-64.

35 Bjarnason I, Macpherson A, Menzies IS. Intestinal permeability: the basics. In: Sutherland LR, Collins SM, Martin F, et al, eds. Inflammatory bowel disease. Basic research, clinical implications and trends in therapy. Dordrecht: Kluwer Academic Publishers, 1994:53-70.

36 Menzies IS Absorption of intact oligosaccharide in health and disease. Biochem Soc Trans 1974;2:1040-6.

37 Laker MF, Menzies IS. Increase in human intestinal permeability following ingestion of hypertonic solutions. F Physiol ability following ingestion

38 Laker MF. The effect of hypertonic solutions on intestinal permeability. MD Thesis, University of London, 1978

39 Dyer NH, Kendall MJ, Hawkins CF. Malabsorption in rheumatoid arthritis. Ann Rheum Dis 1971;30:626-30.

40 Keating J, Bjarnason I, Somasundaram S, et al. Intestina absorptive capacity, intestinal permeability and jejunal histology in HIV and their relation to diarrhoea. Gut 1995;37: 623-9.

41 Lim SG, Menzies IS, Lee CA, et al. Intestinal permeability and function in patients infected with human immunodeficiency virus. Scand $\mathcal{F}$ Gastroenterol 1993;28:573-80.

42 Meling TR, Aabakken L, Roseth A, et al. Faecal calprotectin shedding after short-term treatment with non-steroidal anti-inflammatory drugs. Scand $\mathcal{F}$ Gastroenterol 1996;31: 339-44.

43 Bardhan KD, Bjarnason I, Scott DL, et al. The prevention and healing of acute NSAID-associated gastroduodenal mucosal damage by misoprostol. Br f Rheumatol 1993;32: mucosal

44 Quinn CM, Bjarnason I, Price AB. Gastritis in patients on non-steroidal anti-inflammatory drugs. Histopathology 1993;23:341-8.
45 Hawkey CJ. Non steroidal anti-inflammatory drugs and peptic ulcers. BMF 1990;300:278-84.

46 Fenn GC. Controversies in NSAID-induced gastroduodenal damage- do they matter? Aliment Pharmacol Ther 1994;8:15-26.

47 Melrange R, Gentry C, O'Connor C, et al. Antiinflammatory and gastrointestinal effects of nabumetone or its active metabolite, 6-methoxy-6-naphthylacetic acid (6MNA). Dig Dis Sci 1992;37:1847-52.

48 Ligumski M, Golanska EM, Hansen DG, et al. Aspirin can inhibit gastric mucosal cyclo-oxygenase without causing lesions in the rat. Gastroenterology 1983;84:756-61.

49 Somasundaram S, Rafi S, Hayllar J, et al. Mitochondrial damage: a possible mechanism of the "topical" phase of NSAID-induced injury to the rat intestine. Gut $1997 ; 41$ : 344-53.

50 Brune K, Dietzel K, Nurnberg B, et al. Recent insight into the mechanism of gastrointestinal tract ulceration. Scand $\mathcal{F}$ Rheumatol 1987;16(suppl 65):135-40.

51 Brune K, Schwietzer A, Eckert H. Parietal cells of the stomach trap salicylates during absorption. Biochem Pharmacol 1977;26:1735-40.

52 Brett MA, Greb WH, Kurth HJ, et al. Absence of enterohepatic circulation of the active metabolite of nabumetone. Forschr Med 1988;106:736-7.

53 Insel PA. Analgesic-antipyretics and antiinflammatory agents: drugs employed in the treatment of rheumatoid arthritis and gout. In: Gilman AG, Rall TW, Nies AS, Taylor P, eds. Goodman and Gilman: the pharmacological basis of therapeutics. 8th edn. New York: McGraw-Hill, 1993:63881.

54 Langenbach R, Morham SG, Tiano HF, et al. Prostaglandin synthase 1 gene disruption in mice reduced arachidonic acid-induced inflammation and indomethacin-induced gastric ulceration. Cell 1995;83:483-92.

55 Levine RA, Petokas S, Nandi J, et al. Effects of nonsteroidal anti-inflammatory drugs on gastrointestinal injury and prostanoid generation in healthy volunteers. Dig Dis $\mathrm{Sci}$ 1988;33:660-6.

56 Whittle BJR. Unwanted effects of aspirin and related agents on the gastrointestinal tract. In: Vane JR, Botting RM, eds. Aspirin and other salicylates. London: Chapman \& Hall Medical, 1992:465-509. 